\title{
Stem-Pitting Citrus tristeza virus Predominantly Transmitted by the Brown Citrus Aphid from Mixed Infections Containing Non-Stem-Pitting and Stem-Pitting Isolates
}

R. H. Brlansky and Avijit Roy, University of Florida, Plant Pathology Department, Citrus Research and Education Center, Lake Alfred 33850; and V. D. Damsteegt, Foreign Disease-Weed Science Research Unit, United States Department of Agriculture-Agricultural Research Service, Fort Detrick, MD 21702

\begin{abstract}
Brlansky, R. H., Roy, A., and Damsteegt, V. D. 2011. Stem-pitting Citrus tristeza virus predominantly transmitted by the brown citrus aphid from mixed infections containing non-stem-pitting and stem-pitting isolates. Plant Dis. 95:913-920.

Citrus tristeza virus (CTV) is a phloem-limited Closterovirus that produces a variety of symptoms in various Citrus spp. One of these symptoms is stem pitting (SP). SP does not occur in all Citrus spp. but when it does it may cause low tree vigor, decline, and an economic reduction in fruit size and yield. Historically, the first appearance of CTV-SP in a citrus area often occurs after the introduction of the most efficient CTV vector, the brown citrus aphid (BCA), Toxoptera citricida. Hypotheses for this association range from the introduction of these strains in new planting materials to the increased ability of BCA to transmit SP strains from existing CTV sources. It is known that CTV often exists as a complex of isolates or subisolates. Single and multiple BCA transmissions have been used to separate different genotypes or strains of CTV from mixed CTV infected plants. This study was initiated to determine what the BCA transmits when an exotic severe

are mixed with a non-SP (NSP) isolate, FS627 from Florida. Biological and molecular data was generated from grafted mixtures of these isolates and their aphid-transmitted subisolates. Single-strand conformation polymorphism patterns of the $5^{\prime}$ terminal region of open reading frame $(\mathrm{ORF}) 1 \mathrm{a}$, the overlapping region of ORF1b and ORF2, and the major coat protein gene region of NSP and SP CTV-grafted plants remained unchanged but the patterns of doubly inoculated plants varied. The haplotype diversity within SP isolates B12, B408, and mixtures of NSP and SP isolates (FS627/B12 and FS627/B408) and aphid-transmitted subisolates from doubly inoculated plants was determined by analysis of the haplotype nucleotide sequences. Aphid transmission experiments, symptoms, and molecular analyses showed that SP-CTV was more frequently transmitted with or without NSP-CTV from mixed infections.
\end{abstract} SP CTV isolate B12 from Brazil or B408 from Dominican Republic
In the 1940s, a devastating wilt and decline disease of sweet orange (Citrus sinensis L.) trees on sour orange (C. aurantium L.) rootstock was discovered in a number of citrus-growing areas of the world $(13,37,44)$. Aphids collected from the declining trees transmitted stem-pitting (SP) disease to grapefruit and lime seedlings $(9,43)$. During this same time, a stem- and wood-pitting disease was found on grapefruit (C. paradisi Macfad.) $(4,23,26)$ and a wood-pitting and vein-flecking syndrome was found on lime $(19,21)$. Even though the causal virus was not immediately described, it was later discovered that both diseases were caused by tristeza virus $(9,43)$, which had not been characterized. The causal agent, Citrus tristeza virus (CTV), is now known to be a phloemlimited Closterovirus that contains a single-stranded RNA of 19,226 to 19,302 nucleotides. A variety of biological symptoms in various Citrus spp. are produced by existing CTV strains or genotypes $(11,12)$. The symptoms of decline and death of sweet orange on sour orange rootstock and the wood pitting of numerous Citrus spp. and relatives are well known; however, other CTV symptoms include seedling yellows (SY), vein clearing (VC), tree stunting, and reduced fruit size and yield.

SP-CTV isolates may cause pitting in one Citrus spp. but not in others. CTV isolates frequently cause either orange or grapefruit SP and some isolates cause SP in both hosts, but disease severity

Corresponding author: R. H. Brlansky, E-mail: rhby@ufl.edu

R. H. Brlansky and A. Roy should be considered as co-first authors.

* The $\boldsymbol{e}$-Xtra logo stands for "electronic extra" and indicates that Figure 4 appears in color in the online edition.

Accepted for publication 24 March 2011.

doi:10.1094/PDIS-10-10-0772

(C) 2011 The American Phytopathological Society may differ (11). Low tree vigor and decline and an economic reduction in fruit size and yield are symptoms associated with SP (21). Severe SP has been shown to cause a rope-like appearance on the trunk, limbs, and twigs of the tree (21).

Historically, the appearance of severe CTV in epidemic proportions often corresponds with the introduction of the most efficient CTV vector, the brown citrus aphid (BCA) (Toxoptera citricida (Kirkaldy)). In areas worldwide where sour orange was the chosen rootstock, quick decline and death of trees has occurred upon the introduction of the BCA and the resultant efficient spread of decline-inducing virus strains. The normal response is to replant with rootstocks on which decline does not occur. However, in many countries, the appearance of SP strains of CTV has occurred repeatedly. This could be due to the introduction of SP strains in new planting materials used to replace sour orange rootstock following CTV decline epidemics.

CTV is transmitted in a semipersistent manner by a number of aphid species that include T. citricida, Aphis gossypii Glover, A. spiraecola Patch, T. aurantii Boyer de Fonscolombe, A. craccivora Koch, and Dactynotus jacae L. (28). T. citricida is the most efficient vector compared with A. gossypii; however, A. gossypii has caused epidemic spread of CTV and it can vector certain severe CTV strains (47). Exotic CTV isolates from 10 countries were successfully transmitted by $A$. gossypii to Mexican lime (C. aurantiifolia (L.) Swingle) (47) and the calculated rates for single aphid transmissions ranged from 3 to $11 \%$. A reduction of virulence of some aphid-transmitted subisolates was found. When $T$. citricida is established in a new area with trees on sour orange rootstock, an outbreak of decline of the trees usually occurs shortly after (21). In comparative studies with T. citricida and A. gossypii, Yokomi et al. (48) showed, with five exotic CTV strains, that the single aphid transmission rate of T. citricida was $16 \%$ while that of A. gossypii was $1.4 \%$. In another study, 15 isolates of CTV were transmitted by $A$. gossypii, and 9 of the subisolates obtained showed altered double-stranded (ds)RNA patterns but only minor 
symptom differences in Mexican lime (1). The results further showed that aphid transmission sometimes sorted out the population of the CTV variants as well as the defective RNAs. Brlansky et al. (6) showed that CTV in citrus trees exists as a complex of isolates or subisolates which may contain hidden severe isolates and that the T. citricida can separate parts of the complex. Thus, $T$. citricida may selectively vector these severe SP strains from existing mixtures of CTV. Roy et al. $(30,32)$ has shown the molecular analysis of some of these isolates and their single BCA-transmitted subisolates. Using the aphid vector A. gossypii to transmit the California isolate SY568 (41), it was shown that different symptom variants of the virus were separated and that they ranged from asymptomatic to some more severe than the inoculum source. One asymptomatic subisolate was shown to be different in multiple genomic areas compared with the source CTV genome. This present study was initiated to determine whether the BCA will predominantly transmit severe SP CTV isolates over non-SP (NSP) CTV when the two biological types are mixed in the same host, and to molecularly characterize the mixture and the resultant aphid-transmitted subisolates.

\section{Materials and Methods}

Virus isolates. CTV SP isolates B12 and B408 from the United States Department of Agriculture-Agricultural Research Service (USDA-ARS) Exotic Pathogens Citrus Collection (EPCC), Beltsville, MD were used. In preliminary tests, isolates B12 and B408 were each found to contain a mixture of VT and T3 genotypes. Isolate B408, from the Dominican Republic, causes severe SP and vein corking on sweet orange and grapefruit as well as severe vein clearing and vein corking on Mexican lime. According to the rating system of Garnsey et al. (11), isolate B408 produced more severe $\mathrm{SP}$ in grapefruit (2.4 on a scale of 3 ) than in the sweet orange 'Madame Vinous' (1.4 on a scale of 3 ). Its biological index score according to the method of Hilf et al. (18) is 3. Isolate B12, collected in Brazil, causes severe SP on sweet orange and also has a biological index score of 3 (18). Due to their high biological index scores, these isolates were selected as SP isolates. The Florida isolate FS627 (6) was selected as a common Florida isolate. This isolate was previously reported to be a mixture of mild and severe decline isolates that reacts positively with the mild and decline strain-discriminating monoclonal antibody MCA13 in enzyme-linked immunosorbent assay (ELISA) tests (27). It produces mild VC symptom without vein corking in Mexican lime and does not produce SY in grapefruit. Isolate FS627 does not produce SP symptom in sweet orange or grapefruit. Genotype profiles from multiple molecular markers (MMMs) showed that FS627 is a mixture of T30, T36, and VT genotype isolates (6). FS627 was easily transmissible with both single and multiple BCAs. The resulting aphid-transmitted (AT) subisolates were either MCA13 positive (severe decline) or negative (mild) in double-antibody sandwich (DAS)-ELISA tests (6), indicating that different populations were transmitted in individual single-aphid inoculations. Symptoms of AT subisolates were very similar to the parent FS627 isolate (30).

Plant materials. Sweet orange plants on rough lemon (C. jambhiri Lush) rootstock were graft inoculated with three buds from sweet orange plants containing the isolate FS627. Plant infection was confirmed after 2 months using reverse-transcription polymerase chain reaction (RT-PCR) with the MMMs previously described (6). The infected FS627 plants were then inoculated with three buds from either B12- or B408-infected sweet orange plants. Positive co-infection was confirmed using RT-PCR with the MMMs (6) and genotype-specific primers (GSPs) developed by Roy et al. (29). Thus, the mixtures of FS627 and either B12 or B408 should contain all four genotypes (T36, T30, T3, and VT). Throughout this article, the graft-transmitted mixture of FS627/B12, FS627/B408, and their AT subisolates are labeled as FB12, FB408, and FB12-AT or FB408-AT, respectively.

Aphid transmissions. Aphid transmissions using the BCA were done in biosafety level 3-P containment at the USDA-ARS Foreign Disease and Weed Science Research Unit, Fort Detrick, MD.
Aphids were placed on the source plants containing either FB12 or FB408 and allowed an acquisition access period of $24 \mathrm{~h}$. The aphids were removed and either one or five aphids were placed on individual healthy Mexican lime and sweet orange plants. In all, 10 to 12 lime and sweet orange plants were used in each transmission experiment. Positive controls consisted of transmissions using only isolate B12 or B408. The inoculation access period was $24 \mathrm{~h}$, after which the aphids were removed and the plants were sprayed with $0.25 \%$ malathion to kill any remaining aphids. The plants were maintained in a glasshouse at temperatures of 28 to $30^{\circ} \mathrm{C}$.

Infectivity. Infectivity was determined by visual assessment of vein-clearing symptoms weekly and by ELISA on all the plants after 2 months (27). SP was assessed on stems visually by removing the bark from the shoots. The generic major conserved coat protein gene (CPG) primer pair also was utilized for detection of CTV from all the isolates and AT subisolates $(17,29)$.

Nucleic acid extraction, cDNA synthesis, and PCR amplification. Total plant RNA was isolated from the fully expanded leaves (midrib) and the adjacent bark from the singly and co-infected CTV plants and from the AT plants using the RNeasy Plant Mini Kit (Qiagen, Valencia, CA). Total RNA also was extracted from leaf midribs and bark from healthy Mexican lime and sweet orange plants. MMM primers derived from GenBank genomic sequences were used to amplify three different regions of the CTV genome. The MMM forward and reverse primer pairs $(16,17)$ were used to amplify the major $\mathrm{CPG}$, the $\mathrm{k} 17$ region of open reading frame (ORF) 1a, and the overlapping region of RNA-dependent RNA polymerase $(\mathrm{RdRp})$ and $\mathrm{p} 33$. Throughout this article, the amplified PCR product from the overlapping region of $\mathrm{RdRp}$ and $\mathrm{p} 33$ is designated as POL. In addition, degenerate primer pairs CN487/489, CN488/491, and CN487/491 also were used to amplify 409-, 403-, and 788-nucleotide (nt) fragments, respectively, from the $5^{\prime}$ end of ORF1a of the CTV genome (33). The protocol for RT-PCR amplification was the same as previously reported for other CTV isolates and subisolates (6). The PCR products were analyzed on $1 \%$ agarose gels containing ethidium bromide at 500 $\mathrm{ng} / \mathrm{ml}$. CTV GSPs were used side by side to reconfirm the genotype profile of source, mixed infected, and AT subisolates following the protocol described by Roy et al. (29).

cDNA cloning, single-strand conformation polymorphism, and sequence analyses. The nucleotide sequences from three different regions (nucleotides 697 to 1,484 from the $5^{\prime}$ terminal region, POL, and CPG) of the CTV genome were determined for isolates FS627, B12, B408, FB12, FB408, and their AT subisolates. The RT-PCR amplicons were cloned into a pGEM-T Easy vector (Promega Corp., Madison, WI) according to the manufacturer's protocol. For each RT-PCR amplicon, a minimum of 25 clones were analyzed by single-strand conformation polymorphism (SSCP) using the established protocol $(30,34)$ in order to identify genetic variants in these mixed infected isolates. The nucleotide sequences of the clones with different SSCP mobility patterns were determined using the dye terminator method in an Applied Biosystems Model 3100 genetic analyzer (Perkin-Elmer Corp.) at the University of Florida (DNA Sequencing Core Laboratory). Multiple alignments of all the sequence were performed by using Clustal X (version 1.8; 40), and GeneDoc (version 2.6.002; 25) was utilized to edit alignments and generate a consensus sequence for each primer pair. The MEGA 4 package was used to perform the phylogenetic analyses based on the sequences excluding gapcontaining regions (39). Trees were constructed, after bootstrapping with 1,000 replicates, by the neighbor-joining method using the Kimura-2 parameter. Two other parameters (Jukes-Cantor and Tajima-Nei) also were used for comparison. Minimumevolution and maximum-parsimony methods also were applied in parallel for comparison. Phylogenetic trees based on sequences of the isolates FS627, B12, and B408; mixed isolates FB12 and FB408; and their AT subisolates from the $5^{\prime}$ terminal region, POL, and CPG were rooted by using sequences of the corresponding genes from 20 fully sequenced CTV isolates-T30 (2); T36 (20); T318A (35); T385 (42); VT (22); FS2-2, a Florida VT isolate (45); 
SY568 (46); Mexican CTV isolate (GenBank accession DQ272579); NUagA (38); Qaha from Egypt (AY340974); B165 (31); NZ-B18; NZ-M16 (14); resistant-breaking (RB) NZRB-G90, -M12, -M17, -TH28, and -TH30 (15); HA18-9; and HA16-5 (24) - that were retrieved from the National Center for Biotechnology Information (NCBI) database. The standard genotype isolates T3, T30, T36, and VT isolate B395 from EPCC were used as controls in each experiment.

\section{Results}

Genotype classification of CTV isolates used in this study. Genotype profiles were obtained for isolates FS627 (Fig. 1A), B12, and B408 (Fig. 1B) and for graft-transmitted mixtures of FS627 and B12 (FB12) and FS627 and B408 (FB408) (Fig. 1C) using MMM $(6,16,17)$ and GSP approaches (29) (Table 1). The genotype profile of FS627 was the same as previously published (6), being a mixture of T30, T36, and VT genotypes (Table 1). The SP isolate
B408 was a mixture of the VT and T3 genotypes whereas isolate B12 was a mixture of the VT, T3, and T36 genotypes (Table 1). A mixture of T3, T30, T36, and VT genotypes was found in most of the plants containing the grafted mixtures of FS627 combined with B12 and B408. Four of seven FB408-grafted plants showed complete VT and T3 genotype profiles in 3 months whereas the remaining three plants took another 3 months to become positive for CTV-VT and -T3 genotypes (Table 1).

Aphid transmissions. Single-aphid transmission (SAT) and multiple-aphid transmission (MAT) were successfully done with the B12 and B408 CTV isolates. SAT rates ranged from 50 to $80 \%$ for isolates B12 and B408 while MAT rates ranged from 25 to $75 \%$ for both isolates. The AT studied shows that the SAT was more efficient than the MAT. The genotype profiles of SAT and MAT B12- and B408-infected plants were similar for almost all of the AT subisolates having a profile of a mixture of VT and T3 genotypes (Table 2). Symptoms in the Mexican lime receptors were

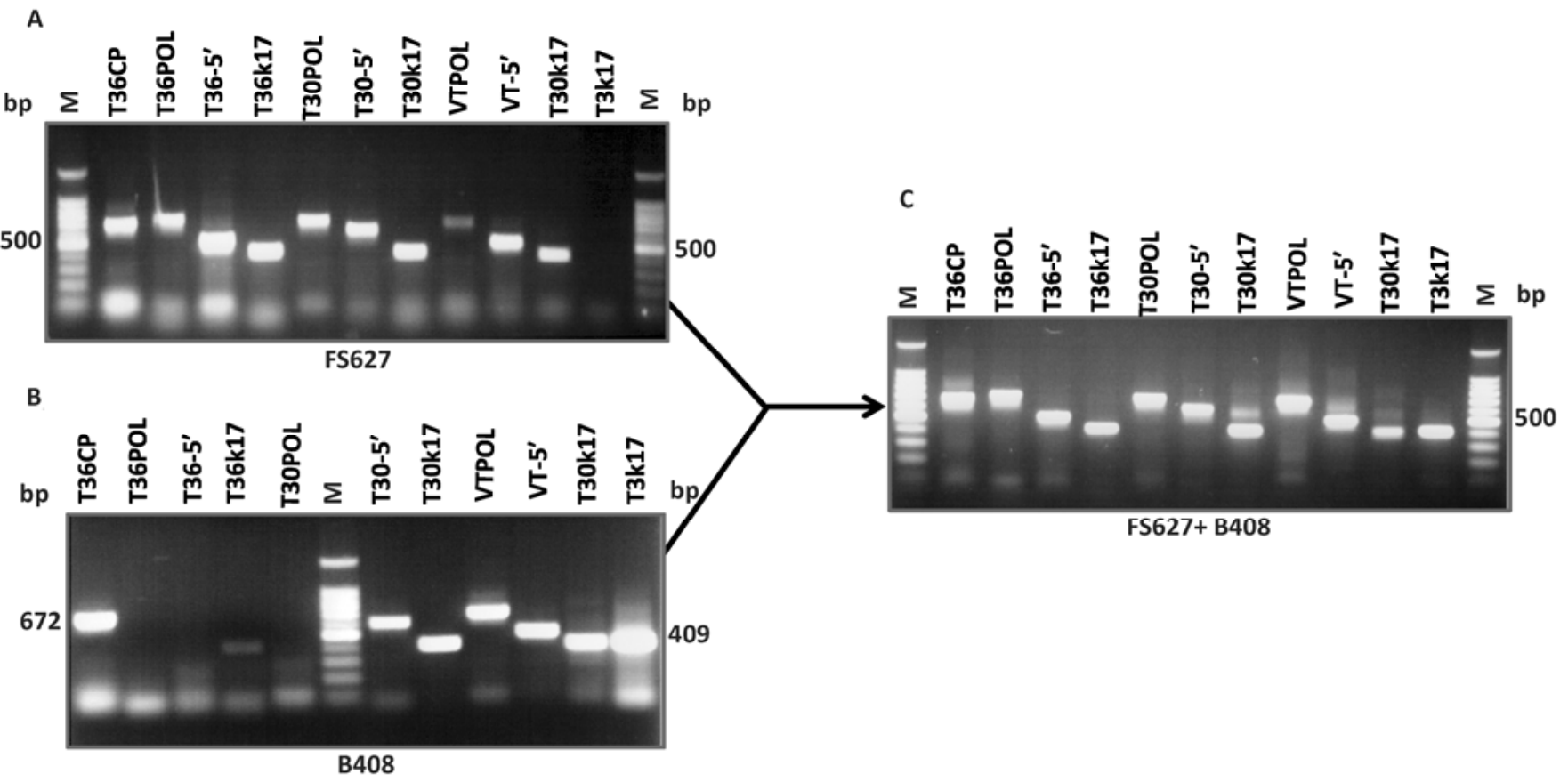

Fig. 1. Genotype profiles of A, non-stem-pitting (NSP) Florida Citrus tristeza virus (CTV) isolate FS627; B, stem-pitting (SP) Dominican Republic CTV isolate B408; and C, NSP and SP mixed infected CTV isolate FS627/B408 (FB408) using multiple molecular marker approach developed by Hilf et al. (17).

Table 1. Genotype profiles of plants infected by Citrus tristeza virus (CTV) isolates FS627, B12, and B408 and grafted mixtures of FS627/B12 and FS627/B408 isolates using the multiple molecular markers (MMMs) approach by Hilf et al. (17) and CTV genotype-specific primers (GSPs) by Roy et al. (29) ${ }^{\mathrm{a}}$

\begin{tabular}{|c|c|c|c|c|c|c|c|c|c|c|c|c|c|c|c|c|}
\hline \multirow[b]{3}{*}{ CTV isolates } & \multicolumn{11}{|c|}{ MMMs } & \multicolumn{5}{|c|}{ CTV primers } \\
\hline & \multicolumn{4}{|c|}{ T36 } & \multicolumn{3}{|c|}{ T30 } & \multicolumn{3}{|c|}{ VT } & \multirow{2}{*}{$\begin{array}{c}\text { T3 } \\
\text { K17 }\end{array}$} & \multirow{2}{*}{$\frac{\text { Generic }}{\text { CPG }}$} & \multicolumn{4}{|c|}{ Genotype specific } \\
\hline & $\mathbf{C P}$ & POL & $5^{\prime}$ & K17 & POL & $5^{\prime}$ & K17 & POL & $5^{\prime}$ & K17 & & & T36 & T30 & VT & T3 \\
\hline FS627 & + & + & + & + & + & + & + & + & + & + & - & + & + & + & + & - \\
\hline B408 & + & - & - & + & - & + & + & + & + & + & + & + & - & - & + & + \\
\hline B12 & + & + & + & + & - & - & + & + & + & + & + & + & + & - & + & + \\
\hline FS627/B408-1 & + & - & - & + & - & + & + & + & + & + & + & + & + & + & + & + \\
\hline FS627/B408-2 & + & + & + & + & + & + & + & \pm & + & + & \pm & + & + & + & + & + \\
\hline FS627/B408-3 & + & + & + & + & + & + & + & + & + & + & + & + & + & + & + & + \\
\hline FS627/B408-4 & + & + & + & + & + & + & + & \pm & + & + & + & + & + & + & + & + \\
\hline FS627/B408-5 & + & \pm & + & + & + & + & + & + & + & + & + & + & + & + & + & + \\
\hline FS627/B408-6 & + & + & + & + & + & + & + & + & + & + & + & + & + & + & + & + \\
\hline FS627/B408-7 & + & + & + & + & + & + & + & \pm & + & + & \pm & + & + & + & + & + \\
\hline FS627/B12-1 & + & + & + & + & + & + & + & + & + & + & + & + & + & + & + & + \\
\hline FS627/B12-2 & + & + & + & + & + & + & + & + & + & + & + & + & + & + & + & + \\
\hline FS627/B12-3 & + & + & + & + & + & + & + & + & + & + & + & + & + & + & + & + \\
\hline FS627/B12-4 & + & + & + & + & + & + & + & + & + & + & + & + & + & + & + & + \\
\hline FS627/B12-5 & + & + & + & + & + & + & + & + & + & + & + & + & + & + & + & + \\
\hline
\end{tabular}

${ }^{a}$ Symbols: + indicates reverse-transcription polymerase chain reaction amplification, - indicates no amplification with the MMMs and GSPs; and \pm indicates amplification by T36POL, VTPOL, and T3K17 primers that took an additional 3 months to became positive. No amplification was obtained with CTVB165 GSP. 
obtained in 4 to 5 weeks and were manifested as chlorotic leaves with severe vein clearing that quickly developed into corky midveins and lateral veins (Fig. 2). In MAT from FB408, transmission rates ranged from 10 to $100 \%$, with an average of $57 \%$ (using 100 seedlings plants). SAT transmission rates with FB408 ranged from 25 to $100 \%$ (using 100 seedlings plants). All ELISA-positive plants had severe symptoms similar to those seen in MAT and SAT with isolate B408 alone. No mild symptoms similar to that seen for

Table 2. Genotype profiles of Citrus tristeza virus (CTV) aphid-transmitted (AT) subisolates obtained from B12, B408, and grafted mixture of FS627/B12 and FS627/B408 isolates infected plants utilizing multiple molecular marker (MMMs) approach by Hilf et al. (17) and CTV genotype-specific primers (GSPs) by Roy et al. (29) a

\begin{tabular}{|c|c|c|c|c|c|c|c|c|c|c|c|c|c|c|c|c|}
\hline \multirow[b]{3}{*}{ Isolates } & \multicolumn{11}{|c|}{ MMMs } & \multicolumn{5}{|c|}{ CTV primers } \\
\hline & \multicolumn{4}{|c|}{ T36 } & \multicolumn{3}{|c|}{ T30 } & \multicolumn{3}{|c|}{ VT } & \multirow{2}{*}{$\begin{array}{c}\text { T3 } \\
\text { K17 }\end{array}$} & \multirow{2}{*}{$\frac{\text { Generic }}{\text { CPG }}$} & \multicolumn{4}{|c|}{ Genotype specific } \\
\hline & $\mathbf{C P}$ & POL & $5^{\prime}$ & K17 & POL & $5^{\prime}$ & K17 & POL & $5^{\prime}$ & K17 & & & T36 & T30 & VT & T3 \\
\hline B408 & + & - & - & + & - & + & + & + & + & + & + & + & - & - & + & + \\
\hline B408-1 & + & - & - & - & - & + & + & + & + & + & + & + & - & - & + & + \\
\hline B408-2 & + & - & - & - & - & - & + & + & + & + & + & + & - & - & + & + \\
\hline B408-3 & + & - & - & - & - & + & + & + & + & + & + & + & - & - & + & + \\
\hline B408-5 & + & _- & - & - & - & - & + & + & + & + & + & + & - & _- & + & + \\
\hline B408-6 & + & - & - & - & - & + & + & + & + & + & + & + & - & - & + & + \\
\hline B408-9 & + & - & - & - & - & + & + & + & + & + & + & + & - & - & + & + \\
\hline B408-13 & + & - & - & - & - & + & + & + & + & + & + & + & - & - & + & + \\
\hline B12 & + & + & + & + & - & - & + & + & + & + & + & + & - & - & + & + \\
\hline B12-1 & + & - & + & - & - & - & + & + & + & + & + & + & + & - & + & + \\
\hline B12-3 & + & - & - & + & - & - & + & + & + & + & + & + & - & - & + & + \\
\hline B12-4 & + & - & - & + & - & - & + & + & + & + & + & + & - & - & + & + \\
\hline B12-5 & + & - & - & + & - & - & + & + & + & + & + & + & - & - & + & + \\
\hline FS627/B408-2.8 & + & + & - & + & + & + & + & + & + & + & + & + & + & + & + & + \\
\hline FS627/B408-2.9 & + & + & + & + & + & + & + & + & + & + & + & + & + & + & + & + \\
\hline FS627/B408-2.10 & + & + & - & + & + & + & + & + & + & + & + & + & + & + & + & + \\
\hline FS627/B408-4.1 & + & - & - & + & - & + & + & + & + & + & + & + & - & + & + & + \\
\hline FS627/B408-4.2 & + & + & - & + & - & + & + & + & + & + & + & + & + & - & + & + \\
\hline FS627/B408-4.3 & + & - & - & - & - & - & + & + & + & + & + & + & - & - & + & + \\
\hline FS627/B408-4.4 & + & - & - & - & - & + & + & + & + & + & + & + & - & - & + & + \\
\hline FS627/B408-4.7 & + & - & - & - & - & - & + & + & + & + & + & + & - & - & + & + \\
\hline FS627/B408-4.8 & + & + & - & - & - & + & + & + & + & + & + & + & + & - & + & + \\
\hline FS627/B408-4.9 & + & + & - & + & - & - & + & + & + & + & + & + & + & - & + & + \\
\hline FS627/B408-4.10 & + & + & - & - & - & - & + & + & + & + & + & + & + & - & + & + \\
\hline FS627/B12-4.1 & + & + & - & + & - & - & + & + & + & + & + & + & + & - & + & + \\
\hline FS627/B12-4.2 & + & - & - & - & - & + & + & + & + & + & + & + & - & - & + & + \\
\hline FS627/B12-4.3 & + & - & + & - & - & - & + & + & + & + & + & + & - & - & + & + \\
\hline FS627/B12-4.4 & + & - & - & - & + & - & + & + & + & + & + & + & - & - & + & + \\
\hline FS627/B12-4.6 & + & - & - & - & - & - & + & + & + & + & + & + & - & - & + & + \\
\hline
\end{tabular}

${ }^{a}$ Genotype profiles of FS627 AT subisolates were described in our previous publication (30). Symbols: + indicates reverse-transcription polymerase chain reaction amplification and - indicates no amplicon with the MMMs and GSPs. No amplification was obtained with CTV-B165 GSP.

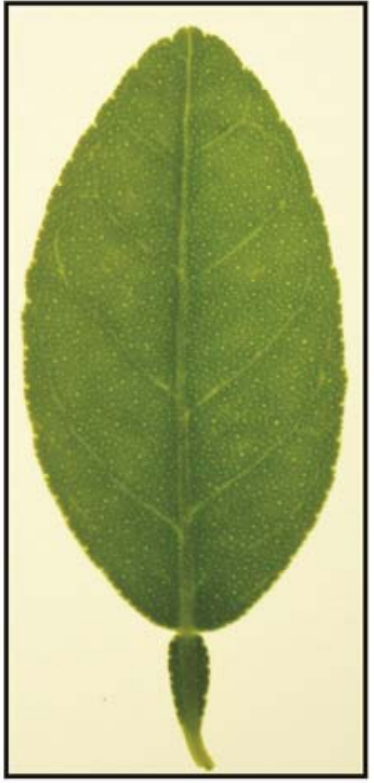

A FS627
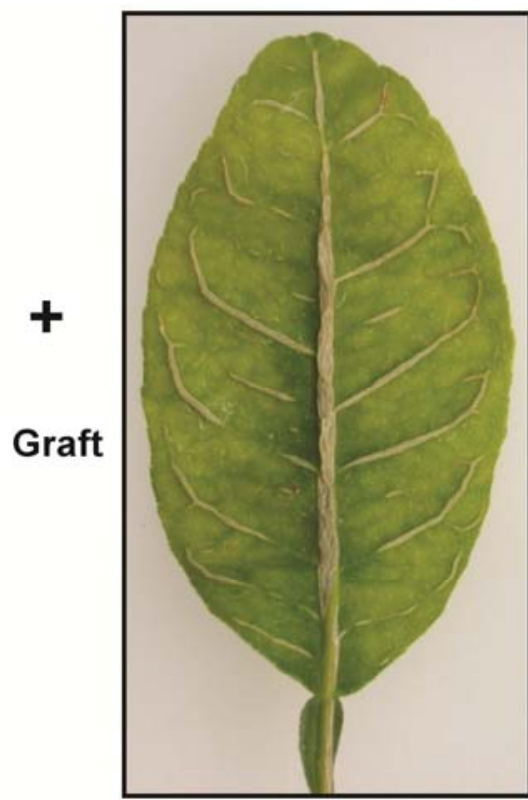

B B408

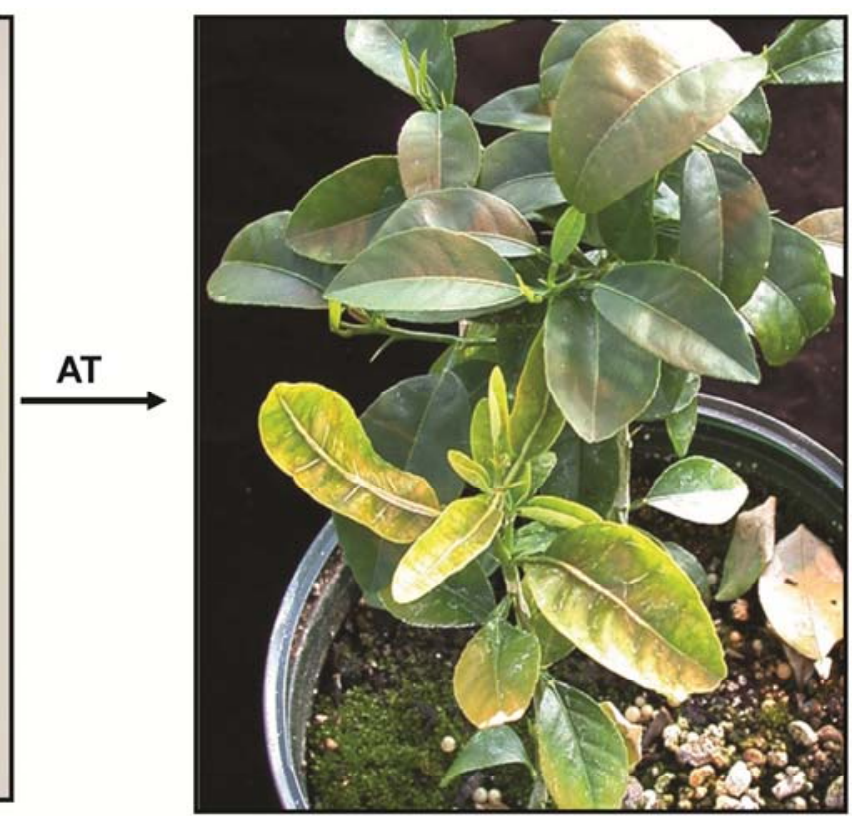

C FS627/B408-AT

Fig. 2. Symptoms produced by Citrus tristeza virus isolate A, FS627; B, B408; and C, the aphid-transmitted (AT) subisolates from mixed inoculated FS627/B408 plants in the Mexican lime indicator host. Mild vein clearing was observed for the FS627 isolate whereas isolate B408 and the AT subisolates produced severe vein-corking symptoms. 
FS627 were found and none of the asymptomatic plants were ELISA positive for CTV. In MAT from FB12, all the receptor plants that tested ELISA positive showed the severe vein clearing and eventual vein corking symptoms similar to those caused by the isolate B12. The percentage of MAT from the FB12 isolate ranged from 30 to $70 \%$ (using 50 seedlings plants), with an average of $47.5 \%$. SAT transmission rates with FB12 ranged from 50 to $100 \%$ (using 50 seedlings plants), with an average of $75 \%$.

Molecular analysis of AT plants. Genotype profiling using the MMM primers showed that all of the ELISA-positive aphid receptor plants from the FB12 and FB408 isolates contained a mixture of genotypes. These data were verified by newly developed GSPs (data not shown). Some, such as plant 2.9 of isolate FB408, contained a complete genotype profile of both isolates whereas others plants, such as FB408-4.3, -4.4, and -4.7, contained only the VT and T3 genotypes and FB408-4.1, -4.2, -4.8, and -4.10 contained either T36 or T30 in addition to the VT and T3 genotypes. Most of the FB12 aphid transmission receptors contained only VT and T3 genotypes, except for plants 4.1 and 4.4. Those plants also contained T30 and T36 genotypes, respectively (Table 2). MMM and GSM analyses confirmed that the BCA always transmitted VT and T3 genotypes from the FB12 and FB408 isolates. Only 27\% of the FB408 AT subisolates contained the T30 genotype and only 36\% of them contained the T36 genotype. Only $17 \%$ of the FB12 AT subisolates contained the T30 and T36 genotypes.

SSCP analysis. The SSCP patterns were derived from the RTPCR-amplified products from the $5^{\prime}$ untranslated region (697 to 1,105 and 1,082 to $1,484 \mathrm{nt}$ ) and CPG region of the mixed isolates FB12 and FB408. All of the FB12- and FB408-infected plants had an electrophoretic profile with multiple bands, which suggested that the genomic RNA population of the grafted isolate mixture contained sequence variants of all probable genotypic isolates in detectable concentrations (Fig. 3). However, some plants had more prominent bands for some of the genotypes. The SSCP results of the 697- to 1,105-nt region in the AT subisolates from B408 and FB408 plants had patterns similar to the B408 isolate (Fig. 3, lanes 14-21). Only a few AT plants had a pattern similar to FB408 (graft-inoculated mixture plant; Fig. 3, lane 13). Comparable results were found with the CPG and 1,082 to $1,484 \mathrm{nt}$ of the $5^{\prime}$ region (data not shown). Similar SSCP analysis results also were obtained from the above-mentioned gene products for the isolate B12, AT subisolates of B12, and AT subisolates of FB12 (Fig. 3, lanes 7-11). Except for AT subisolate 4.1 from isolate FB12 plant number 4, all of the other four AT subisolates had SSCP patterns similar to the B12 isolate and AT subisolates. Two extra banding patterns similar to the T36 genotype were observed in the AT FB12-4.1 subisolate.

Analysis of CTV isolates and AT subisolates based on CPG amplified sequences. The predominant sequence variant of each isolate was chosen based on comparison of SSCP patterns of single cDNA clones with the RT-PCR product pattern from which they had been obtained. The 672-bp RT-PCR-amplified cloned CPG product was sequenced for FS627, B12, B408, FB12, FB408, AT subisolates of FB12, and AT subisolates of FB408 isolates. The comparative analysis showed a high degree of sequence identity among the B12 and B408 isolates. There was 98 to $99 \%$ identity between the B12 and B408 isolates. Both the SP isolates showed 97 to $98 \%$ sequence identity to the Japanese, Spanish, and Californian severe SP isolates (NUagA, T318A, and SY568) and 96\% identity to the Israeli VT isolate. FB12 and FB408 isolates and their AT subisolates showed 96 to $97 \%$ sequence identity with B12 and B408, respectively, and maximum nucleotide identity with the VT isolate (97 to $98 \%$ ).

A phylogenetic tree was constructed from the CPG fragments of the CTV genomic RNA using the neighbor-joining method. Five groups were viewed when T3-, T30-, T36-, and VT-like full-genome nucleotide sequences of CTV were included in the analysis (Fig. 4A). Inclusion of the recently discovered B165 and RB genotypic CTV isolates in the phylogenetic analysis did not change the current genotype grouping of the mixed and AT subisolates (data not shown). The two SP isolates B12 and B408 and the mixed isolates FB12 and FB408 clustered in different clades with other characterized CTV isolates. Phylogenetic tree group IV included the SP isolates B12 and B408 with severe SP isolates NUagA, T318A, and SY568, whereas group III (VT genotype) contained the FB12 and FB408 isolates and their AT subisolates. Groups I, II, and V included the T36, T30, and T3 genotypic isolates, respectively. Isolate FS627 contained T36- and T30-like CPG sequences and occupied both groups I and II in the phylogenetic tree. The nucleotide sequence data was deposited in the NCBI GenBank nucleotide sequence databases under the accession numbers DQ363384 to DQ363391.

The CPG sequences of FB12 and FB408 did not cluster with FS627, B12, and B408. The intragroup (average nucleotide distance between two randomly selected isolates of the same group) diversity of the group III and IV isolates in the phylogenetic tree were $0.013 \pm 0.003$ and $0.016 \pm 0.003$, respectively (Fig. 4A). The intergroup genetic diversity (average nucleotide distance between two randomly selected isolates of two groups) between III and IV was $0.034 \pm 0.006$ and was twofold greater than their intragroup diversity. All the statistical analyses were supported with the topology of the phylogenetic tree.

Analysis of CTV isolates and AT subisolates based on sequences of nucleotides 697 to 1,484 from the $5^{\prime}$ terminal region. The two overlapping primer pairs $\mathrm{CN} 487 / \mathrm{CN} 489$ and CN488/CN491 and the primer pair CN487/CN491 amplified the 697- to 1,484-nt RT-PCR products from all the studied isolates and AT subisolates. In previous studies with AT subisolates of FS627, recombinant sequences were found in the 1,082- to 1,484-nt region (30). In order to determine whether similar recombinations occurred in FB12- and FB408-infected trees and their AT subisolates, analyses of the amplified cloned products of the overlapping regions of 409 and 403 nt were done. The 409-bp RT-PCR amplicon of primer pair CN487/CN489 was sequenced for each of the isolates and AT subisolates. The B12 and B408 SP CTV isolates were

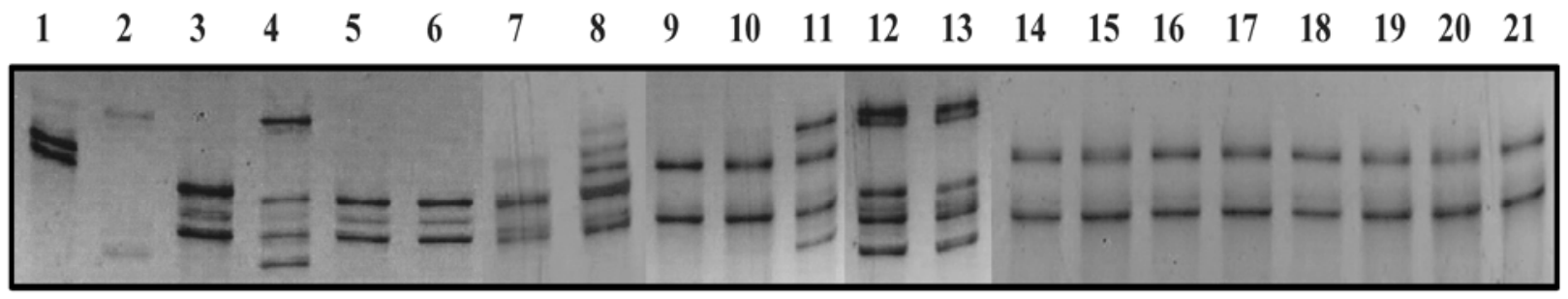

Fig. 3. Single-strand conformation polymorphism patterns from $5^{\prime}$ region (697 to 1,105 nucleotides) of Citrus tristeza virus (CTV) isolates FS627, B12, and B408; mixed isolates FB12 and FB408; and their aphid-transmitted (AT) subisolates compared with standard CTV genotypic isolates. Lane 1, T3; lane 2, T36; lane 3, T30; lane 4, nonstem-pitting isolate FS627; lane 5, isolate VT-B395; lane 6, stem-pitting (SP) isolate B408; lane 7, SP isolate B12; lane 8, FB12 mixed graft-inoculated plant (plants 1-5 showed similar banding patterns); lane 9, AT subisolate from isolate B12 plant number 1 (showed different multiple molecular and genotype profiles than other AT subisolates); lane 10, AT subisolate from isolate B12 (similar banding patterns were found in plants 3-5); lane 11, AT subisolate 4.1 from mixed isolate FB12 plant number 4; lane 12, mixed graft-inoculated isolate FB408 (plants 1-7 showed similar banding patterns); lane 13, AT subisolate 2.9 from FB408 plant number 2; and lane 14, AT subisolates from B408 (all B408-AT subisolates showed similar banding patterns). Lanes 15-21, FB408-AT subisolates from plant number 4 (All FB408-AT subisolates showed similar banding patterns). 
closely related (98\% identity) and had a 96 to $98 \%$ nucleotide identity with the NUagA SY and T318A SP isolates. The haplotype CL-1 of isolate B408 isolate showed $92 \%$ sequence identity with haplotype CL-2 and a 97\% sequence identity with isolate T318A. The grafted mixtures of FB12, FB408, and their AT subisolates had a 98 to $99 \%$ sequence identity among them and were most closely related to T318A and SY568 isolates, with a 95\% nucleotide sequence identity. The two haplotypes of isolate B408 (CL-1 and CL-2) showed 92 and $96 \%$ sequence identity, respectively, with the FB408 isolate. All the sequenced clones of the B12 isolate had only a $93 \%$ sequence identity with the FB12 isolate.

Subsequent overlapping sequences (nucleotides 1,082 to 1,484 ) or a 788-nt amplicon of the same isolates showed similar results. Isolates B12 and B408 shared a 99\% nucleotide identity between them and maximum $98 \%$ identity with the NUagA isolate. Similarly, the mixtures of FB12, FB408, and their AT subisolates shared a 98\% sequence identity with themselves. Both the B12 and B408 isolates shared only an 89 to $90 \%$ sequence identity with mixtures of the FB12 and FB408 isolates and their AT subisolates.

Five groups were displayed in the phylogram (data not shown) when the sequences (697 to 1,105 or 1,082 to $1,484 \mathrm{nt}$ ) of source, mixed, and AT subisolates and T3-, T30-, T36-, and VT-like sequences were compared. A similar phylogenetic tree pattern was produced when we analyzed the total 788-nt amplicon sequences of the studied isolates with the reference isolates from the $5^{\prime}$ terminal region (Fig. 4B). The haplotypes CL-1 and CL-2 of the B408 isolate occupied two different groups (III and IV) in the phylogenetic tree and the maximum pairwise distance between them was $0.081 \pm 0.013$. Similarly, the distance between group V (T3) and groups III and IV was $0.105 \pm 0.015$ and $0.096 \pm 0.015$, respectively, and separated the isolate T3 as a distinct group in the phylogenetic tree. The mean distances within the group containing B12 and B408-CL2 (group IV) and the group containing FB12, FB408, and their AT subisolates (group III) were $0.011 \pm 0.004$ and $0.020 \pm 0.005$, respectively, whereas the mean distance between groups III and IV was $0.072 \pm 0.017$. The intragroup diversity of the B12 and B408 isolates with the FB12 and FB408 mixed isolates were two- to threefold less than their intergroup diversity.
Analysis of CTV isolates and AT subisolates based on genotype-specific POL primer-amplified sequences. The genotypespecific POL primer pairs (T36POL, T30POL, and VTPOL) amplifying approximately 700-nt RT-PCR amplicons obtained from the FS627, B12, B408, FB12, and FB408 isolates and the AT subisolates from mixed infected plants were analyzed. The three POLamplified products from isolate FS627 showed 95 to $99 \%$ sequence identity with VT, T36, and T30, the three components of the FS627 mixed infection (30). The VTPOL-amplified products from the $\mathrm{B} 12$, B408, FB12, and FB408 isolates ranged from 93 to $95 \%$ identical to the type VT isolate. Sequence identity between the B12- and B408VTPOL-amplified product sequences was $99 \%$ but was only 95 to $97 \%$ when we compared the amplified products of FB12 and FB408 mixed isolates and their AT subisolates. Except for the haplotype CL12, two other haplotypes sequences (CL10 and CL13) of FB408 isolate had a 99\% nucleotide identity between themselves and were closely related (94 to $95 \%$ ) to the VT isolate in the POL region.

Phylogenetic relationship of source, mixed, and AT CTV isolates based on genotype-specific POL primers. An approximately 700-nt region of the CTV genomes was analyzed by using three sets of genotype-specific POL primers. Five groups were displayed in the phylogenetic tree when the T3-, T30-, T36-, and VT-like isolates were compared and analyzed (Fig. 4C). The amplified product sequences (T30, T36, and VTPOL) from the isolates FS627, FB12, and FB408 and their AT subisolates represented four different phylogenetic groups (I, II, III, and IV; Fig. 4C). Genotype group III was very closely related to the members of group IV. The intergroup diversity between III and IV was $0.038 \pm 0.006$. Group III consists of the amplified product sequences of FS627-VTPOL and some haplotypes of FB12 and FB408 and their AT subisolates. Isolates B12, B408, and some haplotypes of FB12 and FB408 grouped with the NUagA and T318A isolates in group IV.

\section{Discussion}

In aphid transmission tests, SP CTV was constantly transmitted when mixed with the NSP CTV isolate. The mixed-source isolates

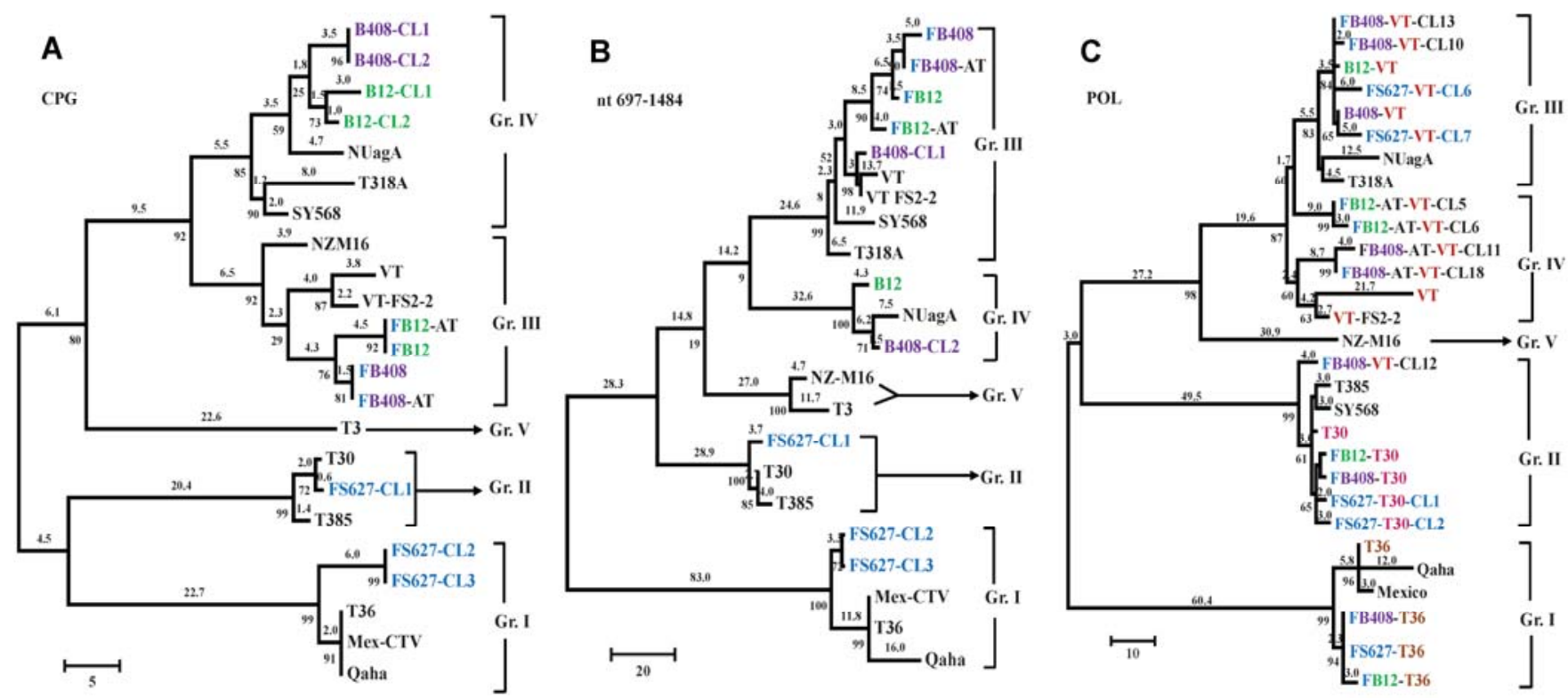

Fig. 4. Phylogenetic trees constructed from the three different regions of the Citrus tristeza virus (CTV) genomic RNA using the neighbor-joining method with Kimura-2 parameter model in MEGA4 program: A, coat protein gene (CPG); B, nucleotides 697 to 1,484 from the $5^{\prime}$ terminal region; and C, POL amplicons from overlapping region of RNA-dependent RNA polymerase and p33. Values at the lower branch point indicate the percentage support for a particular node after 1,000 bootstrap replicates were performed. Branch lengths were calculated using the average pathway method and are shown above the branches. The tree is drawn to scale. Studied isolates FS627, B12, and B408 and mixed isolates FS627/B12 (FB12) and FS627/B408 (FB408) and their aphid-transmitted (AT) subisolates along with T3, T30, T36, and VT genotype-like CTV isolate full-genome sequences were included from the National Center for Biotechnology Information (NCBI) GenBank databases. Nucleotide sequence data of experimental isolates are deposited in the NCBI GenBank under accession numbers DQ363384-DQ363391 (for CPG), DQ363392-DQ363405 (for 697 to 1,105 and 1,082 to 1,484 nucleotides), and DQ357181-DQ355795 (for POL) multiple molecular marker-amplified products. In the color version, the following CTV isolates are indicated: blue for FS627, green for B12, purple for B408, blue-green for mixtures of FS627/B12 and their AT subisolates, and blue-purple for mixtures of FS627/B408 and their AT subisolates. 
and the AT subisolates from these mixtures always produced severe SP symptoms in sweet orange and Mexican lime. Symptoms associated with CTV isolate FS627 such as moderate vein clearing in Mexican lime and no SP in Mexican lime or sweet orange were not found in any of the aphid transmission plants from FB12- and FB408-infected plants. The vein corking and SP in Mexican lime and sweet orange of the AT subisolates were similar to the symptoms of the B12 or the B408 isolate alone in these hosts.

The VT and T3 genotypes were present in both B408 and B12 source plants, as well as in the plants when mixed with the NSP isolate FS627 (Table 1). The T30, T36, and VT genotypes present in FS627 also were found in the graft-inoculated mixtures but the T30 and T36 genotypes were uncommon in AT subisolates from the mixed plants. In a previous study, a similar method was used to show that T36 was the major genotype in the FS627 source isolate rather than the T30 and VT genotypes; however, T30 was the major genotype in most of the FS627 AT subisolates (30). In addition, the T30 genotype had higher overall relative quantities in all three MMM-analyzed regions (3). Aphid transmission for the separation of CTV strains or subisolates has been demonstrated in many studies $(1,6,7,41,47)$. Previous studies have shown that aphid transmission often produces subisolates with altered pathogenic characteristics $(1,6,7,41,47)$, serological reactivity (8), dsRNA profiles and defective RNAs (1), SSCP profiles of the p18 and p20 genes (10), genomic differences (41), and different MMM profiles (6).

AT subisolates from the mixed FB12 and FB408 isolates always contained VT and T3 genotypes. BCA sometimes transmitted T30 and T36 genotypes along with VT and T3 genotypes from the FB408 and FB12 plants. However, analysis of the AT subisolates from FB12 or FB408 mixed isolates (Table 2) showed that the VT and T3 genotypes were transmitted more often than the T30 and T36 genotypes. This would not have been predicted, because the VT genotypes were poorly transmitted from the original NSP isolate FS627 (30). It is possible that the addition of the T3 genotype contributed by either B12 or B408 in the mixed plant might help brown citrus aphids to acquire and transmit the VT genotype predominantly over the T30 and T36 genotypes. However, further research on individual and mixed CTV genotypes with aphid vector interaction is needed to test this hypothesis.

Molecular analysis of the isolates using SSCP of the three different CTV genomic regions produced a diversity of profiles. Plants singly inoculated with isolates FS627, B12, or B408 produced characteristic SSCP profiles, whereas plants doubly inoculated with FS627 and B12 or B408 contained multiple bands characteristic of both NSP and the SP isolates. Interestingly, most of the severe AT subisolates from these sources contained only two DNA bands. In a previous study, Sambade et al. (36) reported that sweet orange plants singly inoculated with a mild or severe isolate yielded an SSCP profile characteristic of the isolate. The SSCP profile of plants inoculated with both isolates was a composite of the two individual profiles. In our study, the SSCP profiles were composites because the NSP FS627 contained three genotypes and had more than two bands. The mixed isolates FB12 and FB408 each contained four CTV genotypes and, therefore, multiple bands were expected in the SSCP profile. However, only two bands similar to those seen with either B12 or B408 were produced. One possibility is that, when isolate FS627 is combined with either B12 or B408, the resulting SSCP may have superimposed banding patterns. A similar situation also was observed in the isolate FS627, where T30 and VT bands were superimposed and displayed as one banding pattern along with the T36 genotype pattern (Fig. 3, lanes 3-5). The SSCP profiles of our three studied regions indicated that the cDNA characteristic for B12 or B408 were predominant over FS627 banding patterns in mixed infected isolates and their AT subisolates. Allyon et al. (5) observed that the SSCP profiles of CTV isolates were composed of haplotypes and that their distribution was altered in different hosts or after aphid transmission. In our study, SSCP and sequence analyses disclosed that the two SP-CTV isolates were most transmissible from mixed infections.
All grafted mixed isolates contained four CTV genotypes (T3, T30, T36, and VT), and the AT subisolates contained at least T3 and VT genotype mixtures. Phylogenetic analysis of the predominant sequences of the CPG and the overlapping regions from the $5^{\prime}$ terminal region (697 to $1,484 \mathrm{nt}$ ) and POL region clearly showed the FS627 NSP isolate was distinct from the SP isolates B12 and B408 and the NSP-SP mixtures of FB12, FB408, and their AT subisolates (Fig. 4A-C). The nucleotide identity of the FB12 and FB408 isolates and the haplotypes of most of their AT subisolates placed them all in VT genotype group III.

The major RNA population in the NSP-SP mixtures was identified as SP and this population continued to predominate in the AT subisolates from these mixtures. In SSCP profiles of the doubly infected plants, characteristic bands of the NSP isolate were possibly present as a minor component, whereas the SP isolate was present as a major component in the NSP-SP mixed infected CTV population. This was supported by the fact that more of the obtained clones were similar to SP sequences. In some cases, there was a high nucleotide divergence between haplotypes of the same isolate. Comparison of these haplotypes with those from other isolates suggests that some CTV isolates could have arisen as result of a mixed infection of two divergent isolates. Alternatively, the haplotypes within a population may have diverged in response to the selection pressures from hosts or vectors. The recently discovered CTV-RB genotype is one of the known examples of a new recombinant CTV genotype. Poncirus trifoliata resistance was broken by the RB strain, which probably evolved from a mixed genotype infection (15). In conclusion, SP CTV was transmitted by the BCA over NSP, becoming the predominant population when in mixtures with NSP isolates. The mechanism for this as well as for the basis of CTV aphid transmission is unknown but this may help to explain the association between the emergence of SP strains and the presence of the BCA. The SP isolate in NSP-SP mixed infections may develop higher titers. It is possible that the increased transmission of SP genotypes over NSP genotypes is simply a question of titer and availability but the actual mechanism for vector acquisition and transmission of SP genotypes is unclear. Regardless, there appears to be a close relation among the BCA, Citrus spp., and CTV, particularly the emergence of SP CTV.

\section{Acknowledgments}

We thank J. Hartung, United States Department of Agriculture-Agricultural Research Service (USDA-ARS), Molecular Plant Pathology Laboratory, Beltsville, MD and W. Schneider, USDA-ARS, Fort Detrick, MD for useful discussion and critical comments on the manuscript; J. Hartung and C. Paul for providing the CTV isolates B12, B395, and B408 from the Exotic Pathogens of Citrus Collection, Beltsville, MD; and the USDA Cooperative State Research Education and Extension Service, Special Tristeza Grant Project 62506 for financial assistance.

\section{Literature Cited}

1. Albiach-Martí, M. R., Guerri, J., Hermoso de Mendoza, A., Laigret, F. Ballester-Olmos, J. F., and Moreno, P. 2000. Aphid transmission alters the genomic and defective RNA populations of Citrus tristeza virus isolates Phytopathology 90:134-138.

2. Albiach-Martí, M. R., Mawassi, M., Gowda, S., Satyanarayana, T., Hilf, M. E., Shanker, S., Almira, E. C., Vives, M. C., López, C., Guerri, J., Flores, R. Moreno, P., Garnsey, S. M., and Dawson, W. O. 2000. Sequences of Citrus tristeza virus separated in time and space are essentially identical. J. Virol. 74:6856-6865.

3. Ananthakrishnan, G., Venkataprasanna, T., Roy, A., and Brlansky, R. H. 2010. Characterization of the mixture of genotypes of a Citrus tristeza virus isolate by reverse transcription-quantitative real-time PCR. J. Virol. Methods 164:75-82.

4. Anonymous. 1950. Stunt bush or stem pitting: a serious disease of Marsh grapefruit. Agric. Gaz. N. S. W. 61:365-366.

5. Ayllon, M. A., Rubio, L., Moya, A., Guerri, J., Moreno, P. 1999. The haplotype distribution of two genes of Citrus tristeza virus is altered after host change in aphid transmission. Virology 255:32-39.

6. Brlansky, R. H., Damsteegt, V. D., Howd, D. S., and Roy, A. 2003. Molecular analyses of Citrus tristeza virus subisolates separated by aphid transmission. Plant Dis. 87:397-401.

7. Broadbent, P., Brlansky, R. H., and Indsto, J. 1996. Biological characterization of Australian isolates of citrus tristeza virus and separation of subisolates by single aphid transmissions. Plant Dis. 80:329-333.

8. Cambra, M., Camarasa, E., Gorris, M. T., Garnsey, S. M., Gumpf, D. J., and 
Tsai, M. C. 1993. Epitope diversity of citrus tristeza virus (CTV) isolates in Spain. Pages 33-38 in: Proc. 12th Conf. Int. Organ. Citrus Virol. P. Moreno, J. V. da Graça, and L. W. Timmer, eds. International Organization of Citrus Virologists, Riverside, CA

9. Costa, A. S., Grant, T. J., and Moreira, S. 1950. A possible relationship between tristeza and the stem pitting disease of grapefruit in Africa. Calif. Citrograph 35:504, 526-528.

10. D’Urso, F., Ayllón, M. A., Rubio, L., Sambade, A., Hermoso de Mendoza, A., Guerri, J., and Moreno, P. 2000. Contribution of uneven distribution of genomic RNA variants of Citrus tristeza virus (CTV) within the plant to changes in the viral population following aphid transmission. Plant Pathol. 49:288-294.

11. Garnsey, S. M., Civerolo, E., Gumpf, D. J., Paul, C., Hilf, M. E., Lee, R. F., Brlansky, R. H., Yokomi, R. K., and Hartung, J. S. 2005. Biological characterization of an international collection of Citrus tristeza virus (CTV) isolates. Pages 75-93 in: Proc. 16th Conf. Int. Organ. Citrus Virol. M. E. Hilf, N. Duran-Vila, and M. A. Rocha-Peña, eds. International Organization of Citrus Virologists, Riverside, CA.

12. Garnsey, S. M., Gumpf, D. J., Civerolo, E. L., Lee, R. F., Roistacher, C. N., Yokomi, R. K., and Bar-Joseph, M. 1987. Toward a standardized evaluation of the biological properties of Citrus tristeza virus. Phytophylactica 19:151-157.

13. Grant, T. J., Costa, A. S., and Moreira, S. 1951. Tristeza disease of citrus in Brazil. Calif. Citrograph 36:310-311, 324-326, 328-329.

14. Harper, S. J., Dawson, T. E., and Pearson, M. N. 2009. Complete genome sequences of two distinct and diverse Citrus tristeza virus isolates from New Zealand. Arch. Virol. 154:1505-1510.

15. Harper, S. J., Dawson, T. E., and Pearson, M. N. 2010. Isolates of Citrus tristeza virus that overcome Poncirus trifoliata resistance comprise a novel strain. Arch. Virol. 155:471-480.

16. Hilf, M. E., and Garnsey, S. M. 2000. Characterization and classification of Citrus tristeza virus isolates by amplification of multiple molecular markers. Pages 18-27 in: Proc. 14th Conf. Int. Organ. Citrus Virol. International Organization of Citrus Virologists, Riverside, CA.

17. Hilf, M. E., Karasev, A. V., Albiach-Martí, M. R., Dawson, W. O., and Garnsey, S. M. 1999. Two paths of sequence divergence in the Citrus tristeza virus complex. Phytopathology 89:336-342.

18. Hilf, M. E., Mavrodieva, V. A., and Garnsey, S. M. 2005. Genetic marker analysis of a global collection of isolates of Citrus tristeza virus: characterization and distribution of CTV genotypes and association with symptoms. Phytopathology 95:909-917.

19. Hughes, W. A., and Lister, C. A. 1953. Lime dieback in the Gold Coast, a virus disease of the lime, Citrus aurantifolia (Christmann) Swingle. J. Hortic. Sci. 28:131-140.

20. Karasev, A. V., Boyko, V. P., Gowda, S., Nikolaeva, O. V., Hilf, M. E., Koonin, E. V., Nibblet, C. L., Cline, K., Gumpf, D. J., Lee, R. F., Garnsey, S. M., and Dawson, W. O. 1995. Complete sequence of the Citrus tristeza virus RNA genome. Virology 208:511-520.

21. Lee, R. F., and Bar-Joseph, M. 2000. Tristeza. Pages 61-63 in: Compendium of Citrus Diseases. L. W. Timmer, S. M. Garnsey, and J. H. Graham, eds. American Phytopathological Society, St. Paul, MN.

22. Mawassi, M., Mietkiewska, E., Gofman, R., Yang, G., and Bar-Joseph, M. 1996. Unusual sequence relationship between two isolates of Citrus tristeza virus. J. Gen. Virol. 77:2359-2364.

23. McClean, A. P. D. 1950. Possible identity of three citrus diseases. Nature 165:767-768

24. Melzer, M. J., Wayne, B. B., Diane, M. S., Stephen, F., Dennis G., and John, S. H. 2010. Genetic diversity and evidence for recent modular recombination in Hawaiian Citrus tristeza virus. Virus Genes 40:111-118.

25. Nicholas, K. B., and Nicholas, H. B., Jr. 1997. GeneDoc: a tool for editing and annotating multiple sequence alignments. www.psc.edu/biomed/genedoc

26. Oberholzer, P. C. J., Mathews, I., and Stiemie, S. F. 1949. The decline of grapefruit trees in South Africa. A preliminary report on so-called stem pitting SP. Union S. Afr. Dep. Agric. Sci. Bull. 297:1-18.

27. Permar, T. A., Garnsey, S. M., Gumpf, D. J., and Lee, R. F. 1990. A monoclonal antibody which discriminates strains of Citrus tristeza virus. Phytopathology 80:224-228.

28. Rocha-Pena, M. A., Lee, R. F., Lastra, R., Niblett, C. L., Ochoa Corona, F. M., Garnsey, S. M., and R. K. Yokomi. 1995. Citrus tristeza virus and its aphid vector Toxoptera citricida: threats to citrus production in the Caribbean and Central and North America. Plant Dis. 79:437-445.
29. Roy, A., Ananthakrishnan, G., Hartung J. S., and Brlansky, R. H. 2010. Development and application of a multiplex reverse transcription polymerase chain reaction assay for screening a global collection of Citrus tristeza virus isolates. Phytopathology 100:1077-1088.

30. Roy, A., and Brlansky, R. H. 2009. Population dynamics of a Florida Citrus tristeza virus isolate and aphid-transmitted subisolates: identification of three genotypic groups and recombinants after aphid transmission. Phytopathology 99:1297-1306.

31. Roy, A., and Brlansky, R. H. 2010. Genome analysis of an orange stem pitting Citrus tristeza virus isolate reveals a novel recombinant genotype. Virus Res. 151:118-130.

32. Roy, A., Choudhary, N., Damsteegt, V. D., Hartung J. S., and Brlansky, R. H. 2010. Complete $3^{\prime}$ end genome analysis of the asymptomatic Citrus tristeza virus isolate B192 and its eight symptomatic single aphid transmitted subisolates. (Abstr.) Phytopathology 100:S111.

33. Roy, A., Manjunath, K. L., and Brlansky, R. H. 2005. Assessment of sequence diversity in the $5^{\prime}$ terminal region of Indian Citrus tristeza virus isolates. Virus Res. 113:132-142.

34. Rubio, L., Ayllón, M. A., Guerri, J., Pappu, H., Niblett, C., and Moreno, P. 1996. Differentiation of Citrus tristeza closterovirus (CTV) isolates by single-strand conformation polymorphism analysis of the coat protein gene. Ann. Appl. Biol. 129:479-489.

35. Ruiz-Ruiz S., Moreno, P., Guerri, J., and Ambrós, S. 2006. The complete nucleotide sequence of a severe stem pitting isolate of citrus tristeza virus from Spain: comparison with isolates from different origins. Arch. Virol. 151:387-398.

36. Sambade, A., Rubio, L., Garnsey, S. M., Costa, N., Muller, G. W., Peyrou, M., Guerri, J., and Moreno, P. 2002. Comparison of the RNA population of pathogenically distinct isolates of Citrus tristeza virus. Application to monitoring cross protection. Plant Pathol. 51:257-265.

37. Schneider, H. 1969. Pathological anatomies of citrus affected by virus diseases and by apparently-inherited disorders and their use in diagnoses. Proc. First Int. Citrus Symp. 3:1489-1494.

38. Suastika G., Natsuaki, T., Terui, H., Kano, T., Ieki, H., and Okuda, S. 2001 Nucleotide sequence of Citrus tristeza virus seedling yellows isolate. J. Gen. Plant. Pathol. 67:73-77.

39. Tamura, K., Dudley, J., Nei, M., and Kumar, S. 2007. MEGA4: Molecular Evolutionary Genetics Analysis (MEGA) software version 4.0. Mol. Biol Evol. 24:1596-1599.

40. Thompson, J. D., Gibson, T. J., Plewniak, F., Jeanmougin, F., and Higgins, D. G. 1997. The Clustal X windows interface: flexible strategies for multiple sequence alignment aided by quality analysis tools. Nucleic Acids Res. 24:4876-4882.

41. Velazquez-Monreal, J. J., Mathews, D. M., and Dodds, J. A. 2009. Segregation of distinct variants from Citrus tristeza virus isolate SY568 using aphid transmission. Phytopathology 99:1168-1176.

42. Vives, M. C., Rubio, L., Lopez, C., Navas-Castillo, J., Albiach-Martí, M. R., Dawson, W. O., Guerri, J., Flores, R., and Moreno, P. 1999. The complete genome sequence of the major component of a mild citrus tristeza isolate. J. Gen. Virol. 80:811-816.

43. Wallace, J. M. 1951. Recent developments in studies of quick decline and related diseases. Phytopathology 41:785-993.

44. Webber, H. J. 1943. The Atristeza@ disease of sour-orange rootstock. Proc. Am. Soc. Hortic. Sci. 43:160-168.

45. Weng, Z., Barthelson, R., Gowda, S., Hilf, M. E., Dawson, W. O., Galbraith, D. W., and Xiong, Z. 2007. Persistent infection and promiscuous recombination of multiple genotypes of an RNA virus within a single host generate extensive diversity. PLoS One 2:e917.

46. Yang, Z. N., Mathews, D. H., Dodds, J. A., and Mirkov, T. E. 1999. Molecular characterization of an isolate of Citrus tristeza virus that causes severe symptoms in sweet orange. Virus Genes 19:131-142.

47. Yokomi, R. K., Garnsey, S. M., Civerolo, E. L., and Gumpf, D. J. 1989. Transmission of exotic citrus tristeza virus isolates by a Florida colony of Aphis gossypii. Plant Dis. 73:552-556.

48. Yokomi, R.K., Lastra, R. , Stoetzel, M. B., Damsteegt, V. D., Lee, R. F. Garnsey, S. M., Gottwald, T. R., Rocha-Pena, M. A., and Niblett, C. N. 1994. Establishment of the brown citrus aphid, Toxoptera citricida (Kirkaldy) (Homoptera: Aphididae) in Central America and the Caribbean basin and its transmission of citrus tristeza virus. J. Econ. Entomol. $87: 1078-1085$. 